\title{
HISTÓRIAS QUE GERAM CANÇÕES, CANÇÕES QUE EVOCAM OUTRAS CANÇÕES
}

LEONORA FIGUEIREDO

CORSINI

Psicóloga e terapeuta de

familia
Polifonia, em música, é uma técnica compositiva que produz uma textura sonora específica, em que duas ou mais vozes se desenvolvem preservando um caráter melódico e rítmico individualizado, contrastando com a monofonia, onde só uma voz existe ou, se há outras, seguem a principal em uníssono ou à distância de oitava(s), ou apenas tecem floreios em torno da principal; à monodia, onde uma voz melódica é acompanhada ou não de acordes sem caráter melódico próprio, e à homofonia e ao contraponto, onde as várias vozes se movem com ritmo idêntico ou muito semelhante de modo a formar acordes nítidos, podendo elas ou não ter um caráter melódico próprio e pronunciado. A palavra vem do grego e significa várias vozes. (Fonte: Wikipedia)

edição de dezembro de 2017 da revista Nova Perspectiva Sistêmica trouxe alguns artigos que me fizeram revisitar as possibilidades estéticas, poéticas e relacionais que fazem parte dos processos terapêuticos e das variadas experiências de acolhimento, conexão e relação neles descritos. Um deles ecoou de maneira especial: "Polifonias: canções para conversar", texto composto por muitas mãos e várias vozes, resultado da apresentação dos autores José Luis Rodríguez Fiestas, Carlos Expósito Afonso e Juan Báez Garcia no III Congresso Internacional de Práticas Colaborativas e Dialógicas (Tenerife, Ilhas Canárias, abril de 2017) a partir do trabalho que desenvolvem no serviço especializado em intervenção com adolescentes atendidos pela Asociación Solidaria Mundo Nuevo, em Tenerife.

Várias passagens me tocaram, a começar pelo convite feito pelos autores, implícito ao longo do texto e explicitado no final, de que as reflexões e afetações dos leitores gerem novas reflexões e conversas. Os autores descrevem este seu desejo também como uma busca de autocuidado porque, como dizem, nós, terapeutas, somos pessoas que trabalhamos com pessoas, tratando, portanto, de nos cuidarmos para poder cuidar; além disso, e não menos importante, nem toda conversa é por si só dialógica ou generativa: aprendemos a "estar" nesta disposição. Às muitas vozes já presentes na metodologia do trabalho que foi sendo desenvolvido naquele contexto institucional das Ilhas Canárias somaram-se as vozes de outros adolescentes atendidos na instituição, bem como de outros participantes no trabalho, convidados a entrar num processo de ir e vir dialógico a que os autores dão o nome de "cancionear".

Assim, talvez inspirada pelo próprio título do artigo, fui fazendo a leitura como quem ouve uma canção pela primeira vez, me deixando "tocar" primeiro pela melodia, pelos sons, buscando, depois, pela letra, lendo/ouvindo uma outra vez, pensando em outras canções, ou histórias que poderiam virar canções, outras canções que se conectam com as histórias narradas. Nada mais adequado, portanto, para estar na seção "Ecos" da Revista... 
Polifonia, diálogos colaborativos, construção e reconstrução de narrativas, conversas sobre conversas são ingredientes que costumam fazer parte de um cardápio de pressupostos e abordagens terapêuticas críticas a discursos monovocais e ao paradigma da autoridade/verdade das teorias científicas; são abordagens que se desenvolvem em torno de premissas de caráter sempre relacional, processual, contextual e situado da produção do conhecimento em terapia.

Além desses recursos, gosto de colocar em destaque a dimensão poética da intervenção terapêutica, formulação inovadora nas terapias pós-modernas, mas talvez nem sempre explorada em textos e relatos sobre terapia na forma original como fazem os autores de "Polifonias". E onde podemos sentir, onde podemos enxergar esta dimensão poética na narrativa construída pelos autores? Édouard Glissant, pensador e poeta martinicano que muito admiro, redefinia os encontros entre diferenças, a entrada na Relação (que ele preferia grafar assim mesmo, em letra maiúscula) como Poética da Relação $(2003,2005)$. O trabalho de Glissant se situa em um campo teórico que costuma ser denominado por "estudos caribenhos" ou "estudos pós-negritude". Nesse campo são estudadas diferentes formas de expressão que compõem o que ele chama de "poética": Poética da Relação, Poética da Diversidade, Poética da Creolização, e assim por diante. A obra de Glissant compõe uma poética porque ele utiliza livremente conceitos, palavras, termos, reinventa-os, subverte-os, faz trabalhar uma língua na outra. Assim, a partir do sentido postulado por Glissant, podemos imaginar que uma terapia que tenha em seu cerne o relacional e o conversacional será sempre poética.

John Shotter (1996), por sua vez, nos falava da poética social sobretudo como um postura metodológica para pesquisas em que a ênfase deveria ir para os processos em detrimento dos conteúdos, privilegiando as vivências práticas em lugar das teorias e conhecimentos codificados. Como escreve Carla Guanaes (2017) em um artigo-depoimento sobre os impactos de seu encontro com John Shotter em seus trabalhos de pesquisa: "No mundo das práticas do cotidiano, a linguagem objetiva com que costumamos descrever o que vivemos dá lugar ao poético, à linguagem imprecisa das metáforas e da imaginação". Trazendo para o terreno das interações terapêuticas sempre que abrimos espaço para novas conexões, para irmos além do esperado, para buscarmos uma nova compreensão das redes de conexões e relações entre eventos, substituindo a linguagem do único pela linguagem da multiplicidade e do performativo, estamos assumindo uma poética social.

Já Marcelo Pakman (2011) traduz a dimensão poética na terapia como "pontos de indeterminação que escapam à tirania da técnica e da teorização apriorística", processo que nomeia como "micropolítica", numa acepção muito particular. Assim, uma palavra, um gesto, o vislumbrar de uma emoção, a vacilação de uma voz, os fragmentos de uma lembrança, uma pausa desmedida tornam-se lugares onde um evento poético pode emergir, se formos sensíveis à sua presença marginal. A qualidade poética da terapia estaria justamente em poder transformar isto que emerge em possibilidade para todos os que participam da relação terapêutica de serem outros, para além das identidades consensuais forjadas pelas forças "micropolíticas" que nos atravessam e nos rotulam. Seria, ainda segundo Pakman, a capacidade de abrir espaço na terapia para a expressão da vida em sua singularidade e àquilo que permite que essa singularidade se expresse em eventos únicos e insubstituíveis que conferem aos encontros terapêuticos sua qualidade poética. 
Voltando ao nosso texto, as vozes de José, Carlos e Juan vão se fazendo ouvir em diferentes momentos, entretecidas na narrativa feita em torno da canção composta pela adolescente $Y$, atendida na instituição. Depois de escutar uma canção proposta pelo terapeuta, $Y$ pôde retirar uma nova canção de dentro si, deixou-a vir à tona para, através dela, expressar suas emoções, suas dúvidas, seus anseios, aquilo que até então ela não conseguia traduzir em palavras. Enxergo aí uma das qualidades poéticas do trabalho apresentado pelos três autores. Embora, como dizem, já tivesse sido possível vislumbrar o poder transformador que a música tem sobre as pessoas, a canção de $Y$, cuja letra é muito bela e muito forte, ficou ainda por um tempo ecoando e vibrando com uma carga emocional pesada para o terapeuta que havia atendido a jovem. Este terapeuta soube poeticamente "ir além" ao convidar os companheiros do serviço a ouvir a canção e depois compartilhar seus sentimentos. Novas conexões foram sendo criadas, não apenas entre os terapeutas, mas de cada um consigo mesmo, com suas dificuldades singulares em expressar sentimentos, em admiti-los e falar deles. Numa composição de conversas e canções, parte da história de alguém passa a ser também parte da própria história, e assim se transformam histórias em canções e canções em tema de conversa, com efeitos mútua e responsivamente (como diria Shotter) terapêuticos. Este processo de compor e compartilhar canções e os sentimentos e reflexões por elas suscitados é descrito pelos autores como "plano revolucionário" no mundo da terapia.

\section{SE A MIM ME AJUDA, A OUTRAS PESSOAS TAMBÉM PODERIA AJUDAR}

As passagens entre o singular e o coletivo do processo desenvolvido a partir das canções com e para adolescentes da instituição também apontam outra qualidade para a qual muitos terapeutas têm se voltado, a qualidade polifônica. Ao ouvir uma história, fazemo-la nossa; nas palavras dos autores, "minha voz inclui as vozes deles, quando conto a minha/nossa história, passo do eu ao nós". Isto me faz lembrar do conceito de Mikhail Bakhtin de sujeito polifonicamente constituído: aquele que volta a si mesmo enriquecido com as outras vozes de suas interações linguísticas. Polifonia, em Bakhtin, é um gênero literário, mas remete igualmente à ideia de interações abertas, inacabadas, cada interação tendo potencial evocatório para abrir para outra interação, num encadeamento sem fim de enunciados. Seguindo a teorização de Bakhtin, em todo enunciado ressoam palavras do outro enunciado em maior ou menor grau de explicitação. Os enunciados não são indiferentes uns aos outros nem autossuficientes, conhecem-se uns aos outros, refletem-se mutuamente. São precisamente esses reflexos que lhes determinam o caráter. O enunciado está repleto de ecos e lembranças de outros enunciados, aos quais está vinculado no interior de uma esfera comum da comunidade verbal.

Cada um dos elementos significativos isoláveis de uma enunciação e a enunciação toda são transferidos nas nossas mentes para um outro contexto, ativo e responsivo. A compreensão é uma forma de diálogo; ela está para a enunciação assim como uma réplica está para a outra no diálogo. (Bakhtin, 1981) 
No encerramento do texto "Polifonias: canções para conversar", os autores utilizam uma bela metáfora da viagem que continua que me evocou uma canção que fala de pés na estrada. Como numa roda de terapia comunitária em que é comum convidar alguém para cantar uma canção, trazer um conto ou uma poesia que tenha conexão com os temas trazidos para a conversa, permito-me compartilhar aqui uma canção que a história de $Y$ me fez lembrar. Trata-se de uma canção política, um clássico da música popular brasileira que fala do amanhã, da esperança e da crença nas transformações:

\section{Nada será como antes \\ (Milton Nascimento e Ronaldo Bastos - Clube de Esquina 1)}

Eu já estou com o pé nessa estrada

Qualquer dia a gente se vê

Sei que nada será como antes, amanhã

Que notícias me dão dos amigos?

Que notícias me dão de você?

Alvoroço em meu coração

Amanhã ou depois de amanhã

Resistindo na boca da noite um gosto de sol

Num domingo qualquer, qualquer hora

Ventania em qualquer direção

Sei que nada será como antes amanhã

Que notícias me dão dos amigos?

Que notícias me dão de você?

Sei que nada será como está

Amanhã ou depois de amanhã

Resistindo na boca da noite um gosto de sol

\section{REFERÊNCIAS}

Bakhtin, M. (1981). Marxismo e Filosofia da Linguagem (2a ed.) São Paulo: Hucitec.

Glissant, É. (2003). Poetics of Relation. Ann Arbor, MI: University of Michigan Press.

Glissant, É. (2005). Introdução a uma poética da diversidade. Juiz de Fora, MG: Editora UFJF. 
Guanaes-Lorenzi, C. (2017) Dialogismo Performativo: Mi Experiencia de Diálogo con John Shotter. International Journal of Collaborative-Dialogic Practices, Special Issue, $7(1), 28-32$.

Pakman, M. (2011). Palabras que permanecen, palabras por venir: micropolítica y poética en psicoterapia. Barcelona: Editorial Gedisa.

Shotter, J. (1996). Social construction as social poetics: Oliver Sacks and the case of Dr. P. In B Bayer \& J. Shotter (Eds.), Reconstructing the Psychological Subject (pp. 33-51). Londres: Sage Publications.

\section{LEONORA FIGUEIREDO CORSINI}

Psicóloga, terapeuta de família, mestre em Psicologia (UFRJ) e doutora em Serviço Social (UFRJ). Integra a equipe clínica do Instituto Noos, em São Paulo E-mail: corsinileonora@gmail.com 